\title{
Habilidades Sociais Educativas, Relacionamento Conjugal e Comportamento Infantil na Visão Paterna: Um Estudo Correlacional
}

\author{
Aline Costa Fantinato \\ Fabiana Cia \\ Universidade Federal de São Carlos \\ São Carlos, SP, Brasil
}

\begin{abstract}
RESUMO
A interação entre pais e filhos pode influenciar o comportamento das crianças, sendo necessário investigar especificamente quais os comportamentos parentais podem interferir no desenvolvimento infantil. Sendo assim, este estudo teve por objetivos: a) descrever as habilidades sociais educativas paternas, o relacionamento conjugal e os comportamentos infantis segundo a avaliação dos pais (homens) e (b) relacionar as habilidades sociais educativas paternas, o relacionamento conjugal e os comportamentos infantis. Participaram 40 pais de crianças em idade préescolar que responderam ao Roteiro de Entrevista de Habilidades Sociais Educativas Parentais, Questionário de Relacionamento Conjugal e Questionário de Capacidades e Dificuldades. Os resultados apontaram para a relação entre o baixo repertório de habilidades sociais educativas com variáveis negativas do relacionamento conjugal e problemas de comportamento das crianças, assim como, quanto melhor as habilidades sociais educativas, melhor a avaliação da relação conjugal e melhor também o repertório comportamental infantil.
\end{abstract}

Palavras-chave: Habilidades sociais educativas; Pai; Relacionamento conjugal; Problemas de comportamento; Habilidades sociais infantis.

\section{ABSTRACT}

Educational Social Skills, Marital Relationship and Child Behavior According to Fathers: A Correlational Study

The interaction between parents and children can influence the children's behavior. It is necessary to investigate specifically which parental behaviors can interfere in child development. Therefore, this study aimed to: a) describe the paternal educational social skills, marital relationships and child behavior as assessed by fathers and (b) relate the paternal educational social skills, marital relationships and child behavior. Participants were 40 fathers of children of preschool age who answered the Parental Educative Social Skills Interview Script, Marital Relationship Questionnaire and Strengths \& Difficulties Questionnaire. The results showed a relationship between low educational repertoire of social skills and negative variables of marital relationship and behavioral problems of children, and also that, the better the educational social skills, the better the evaluation of the marital relationship and the better the children's behavioral repertoire.

Keywords: Educational social skills; Father; Marital relationship; Behavior problems; Children's social skills.

\section{RESUMEN}

Habilidades Sociales Educativos de Relación Marital y la Conducta de los Niños en la Perspectiva del Padre: Un Estudio Correlacional

La interacion entre los padres y con sus hijos pueden influir en el comportamiento de los niños, es necesario investigar qué comportamientos padres pueden interferir em el desarrollo del niño. Por lo tanto, este estudio tuvo como objetivo: a) describir las habilidades paternales educativos sociales, las relaciones de pareja y el comportamiento del niño según la evaluación de los padres (hombres) y (b) se relacionan las habilidades sociales educativos paternos, relaciones conyugales y conductas Niños tales como aquellos que pueden hacer daño. Los sujetos fueron 40 padres de niños en edad preescolar que respondieron a Guión de Entrevista de Habilidades Sociales Educativas de los Padres, Cuestionario de relación matrimonial y Cuestionario de Capacidades y Dificultades. Los resultados mostraron que huvo relación entre un bajo repertorio de habilidades educativas sociales con variables negativas de la relación conyugal y los problemas de conducta de los niños, así como cuánto mejores las habilidades educativas sociales, una mejor evaluación de la relación matrimonial y también de repertorio conductual de los niños.

Palabras clave: Habilidades sociales educativas; Padre; La relación conyugal; Problemas de conducta; Habilidades sociales de los niños. 


\section{INTRODUÇÃO}

As interações estabelecidas no contexto familiar são influenciadas por diversos fatores, que podem tanto contribuir para uma boa relação entre seus membros, como provocar prejuízos na mesma. Tais fatores são tanto os que pertencem à própria dinâmica familiar, como características do relacionamento conjugal e práticas parentais, como também os de fora da família, como o emprego dos pais, escola e rede social (Dessen \& Braz, 2005).

Neste contexto, as habilidades sociais educativas parentais são de suma importância para o estabelecimento de uma relação afetuosa entre pais e filhos. Del Prette e Del Prette (2001) as definem como sendo as habilidades sociais que têm o propósito intencional de promover o desenvolvimento e aprendizagem do outro, sendo específicas ao contexto familiar ou escolar de educação das crianças e constituem a base das estratégias educativas dos pais em relação aos filhos. Além disso, o caráter intencional prevê que o agente educativo tenha um objetivo definido para controlar ou ensinar comportamento às crianças. Na definição de BolsoniSilva e Loureiro (2010) habilidades sociais educativas são o conjunto de habilidades sociais, especificamente dos pais, aplicáveis às práticas educativas de seus filhos.

Alguns estudos evidenciaram a relação entre as habilidades sociais e as práticas educativas utilizadas por pais com os comportamentos e desempenho acadêmico apresentados por seus filhos (Richmond \& Stocker, 2008; Leme \& Bolsoni-Silva, 2010; Cia Barham e Fontaine, 2010). Pais com melhor repertório de habilidades sociais educativas tendem a utilizar práticas educativas adequadas com a prole, facilitando que os filhos emitam mais comportamentos adequados nas interações sociais. É importante frisar que as interações são relações bidirecionais, em que o comportamento de um afeta o outro, ou seja, o modo com que os pais se comportam influencia o comportamento dos filhos, assim como o comportamento destes afeta a maneira que o pai lida com ele (Dessen \& Braz, 2000).

O estudo de Cia e Barham (2009) examinou as relações entre a participação do pai nos cuidados com a criança, autoconceito e desempenho acadêmico. Os dados do estudo apontaram para relações positivas entre a frequência de participação do pai nos cuidados com os filhos, autoconceito e desempenho acadêmico.

Quanto às relações familiares, a literatura aponta que os conflitos conjugais acarretam em prejuízos para as crianças, apontando tanto para relações diretas, como indiretas (Grych \& Fincham, 1990; Ablow et al., 2009), pois, primeiramente, os pais são modelos para os filhos, sendo assim, quando exposta à agressividade entre o casal, a criança aprende a se comportar desta forma, reproduzindo comportamentos violentos com os pares e adultos de sua convivência (Katz \& Gottman, 1993). Grych e Fincham (1990) levantam a hipótese de que o conflito marital expõe as crianças a uma intensa fonte de estresse, levando-as a apresentar a agressividade ou retraimento como resposta às situações vivenciadas. Emery e Tuer (1993) apontam que a existência de conflitos entre o casal interfere no relacionamento que os pais vão estabelecer com seus filhos e vice-versa.

De acordo com Benetti (2006); Lindsey, Caldera e Lankersley (2009) e Villas Boas, Dessen e Melchiori (2010) crianças expostas a conflitos conjugais frequentes são mais vulneráveis a apresentar problemas de comportamento, como comportamentos agressivos e depressão, por exemplo. Quando os pais estão satisfeitos com seus cônjuges, tendem a ser mais atenciosos e carinhosos com a prole. No entanto, quando estão insatisfeitos, se envolvem menos com os filhos, especialmente os homens. Quando os pais têm conflitos conjugais tendem a usar práticas parentais inconsistentes e abuso físico contra as crianças.

O estudo de Loos e Cassemiro (2010) aponta para a relação entre o clima conjugal positivo e felicidade e satisfação nas crianças, enquanto que o clima conjugal negativo apresentou correlações negativas com autoconceito geral, expectativa de controle e agência de esforço. Além disso, o estudo mostrou que o uso de punições inadequadas e comunicação negativa com os filhos se correlacionaram negativamente com o status intelectual e acadêmico dos participantes.

Em uma revisão de estudos sobre fatores de riscos ao desenvolvimento infantil, Slack et al. (2011) notaram que fatores econômicos, estresse parental e agressão física estavam positivamente correlacionados com a negligência dos pais para com os filhos. Por outro lado, quanto maior o senso de autoeficácia dos pais, a qualidade da relação com o pai e indicadores de bem-estar da criança, menor a probabilidade da criança ser negligenciada.

Estreitando o foco para a relação com o pai, as pesquisas têm apontado que a baixa qualidade da relação com este está diretamente associada à existência de problemas de comportamento apresentados por seus filhos. Por exemplo, pai que não se interessa pelas atividades do filho (Coley, Morris, \& Hernandez, 2004; Flouri, 2005; Cia \& Barham, 2009), que é negligente e/ou utiliza práticas educativas punitivas e autoritárias para com seu filho e que não oferece suporte emocional e afeto ao filho tem sido identificado como fator de risco para o aparecimento de problemas de comportamento 
nas crianças, tanto no ambiente escolar quanto no ambiente familiar (Dunn, 2004; Patterson; Mockford $\&$ Stewart-Brow, 2005).

Jia, Kotila e Schoppe-Sullivan (2012) realizaram um estudo com o propósito de analisar as associações recíprocas entre o envolvimento do pai em atividades de jogo e cuidado com a criança e a adaptação da criança do comportamento favorável. Participaram do estudo, 112 famílias com filhos em idade pré-escolar. Os pais responderam sobre o seu envolvimento com os filhos, enquanto que mães e professoras relataram sobre o comportamento das crianças. Os resultados mostraram que o envolvimento do pai em atividades de jogo diminui os problemas de comportamento externalizantes e internalizantes e aumentou a competência social na escola das crianças.

De modo geral, as pesquisas apontam um maior envolvimento do pai nos cuidados e na educação dos filhos, quando comparado com gerações anteriores. No entanto, tal envolvimento não é uniforme em todas as famílias. Tais resultados podem estar relacionados com a questão cultural, já que o maior envolvimento dos pais com as crianças e a divisão de tarefas domésticas é algo recente, e esses comportamentos sempre foram esperados da mulher, pois muitos ainda esperam do pai, o papel de provedor financeiro (De Oliveira \& Silva, 2011). Ressalta-se que o papel do pai e seu maior envolvimento nos cuidados e na educação dos filhos compreendem variáveis importantes, uma vez que o envolvimento paterno é considerado um fator de proteção ao desenvolvimento infantil (Dessen \& Braz, 2005; Cia \& Barham, 2009).

O ajustamento conjugal, as formas de comunicação e as estratégias de resolução de conflitos utilizadas pelo casal influenciam os padrões de cuidado com as crianças e a qualidade das relações pais- filhos. Em um estudo realizado por Chan (2011) sobre a relação entre a violência conjugal e maus tratos infantis, é possível notar que crianças expostas à violência conjugal são mais vulneráveis a vitimização de maus tratos infantis. As crianças participantes deste estudo relataram ter experienciado castigo corporal, maus tratos físicos, agressão psicológica e negligência, sendo que a violência contra o parceiro foi um fator associado com todas as formas de maus tratos infantis.

Durand, Schraiber, França-Junior e Barros (2011) realizaram um estudo sobre as consequências da violência entre o casal sobre o desenvolvimento de crianças, com idade entre cinco e 12 anos. Percebeu-se que as crianças expostas à violência física ou sexual entre os pais apresentavam altos índices de problemas de comportamento, como agressividade, por exemplo, além de um baixo desempenho acadêmico.
Desta forma, percebe-se que uma relação conjugal insatisfatória, acarreta não só em prejuízos para os cônjuges, como também para os filhos (Bolsoni-Silva \& Marturano, 2010; Dessen \& Braz, 2000). Para Caballo (2003) em uma relação entre duas pessoas, qualquer que seja o tipo de relação, as pessoas tendem a esforçar-se para maximizar as consequências positivas ou agradáveis e, ao mesmo tempo, reduzir ao máximo as consequências negativas ou desagradáveis. Assim, a relação de um casal é avaliada como satisfatória e mantida à medida que cada um dos cônjuges percebe que recebe mais consequências positivas que negativas de seu parceiro. Uma hipótese levantada por este autor referente aos conflitos conjugais prejudiciais decorre da existência de déficits de habilidades sociais, por parte de um ou de ambos os membros do casal, especialmente quanto às habilidades de comunicação e solução de problemas.

Nota-se que o impacto dos conflitos conjugais é mais negativo para o relacionamento paterno, pois os homens tendem a ser menos disponíveis afetivamente e a demonstrarem menos interesse pelas atividades dos filhos quando estão em um relacionamento conjugal conflituoso. Acredita-se que o modo que os pais se relacionam com seus filhos têm ligação direta com os comportamentos destes (Silva \& Cia, 2012). Além disso, sabe-se que os problemas de comportamento acarretam em prejuízos para o desempenho social e acadêmico da criança. Os problemas de comportamento são classificados em dois grupos, os externalizantes, que são expressos em relação às outras pessoas, como vandalismo, agressões físicas e verbais, e em internalizantes, que são aqueles expressos em relação a si próprio, como depressão, isolamento, choro, entre outros (Gargiulo, 2003; Del Prette \& Del Prette, 2005; Gresham, 2009).

A fim de compreender a visão que o homem tem de seus comportamentos nas interações familiares e suas correlações com comportamentos infantis, este estudo teve por objetivos (a) descrever as habilidades sociais educativas paternas, o relacionamento conjugal e os comportamentos infantis segundo a avaliação dos pais (homens) e (b) relacionar as habilidades sociais educativas paternas, o relacionamento conjugal e os comportamentos infantis.

\section{MÉTODO}

\section{Participantes}

Participaram da pesquisa 40 pais (homens) de crianças pré-escolares. A média de idade dos pais foi igual a 37 anos e as crianças tinham idade entre quatro e seis anos de idade. 
Foram utilizados como critérios para ser participante: o pai se interessar em participar da pesquisa, estar empregado ou exercendo atividade remunerada, a criança estar matriculada em uma pré-escola e morar com ambos os pais biológicos.

\section{Local de coleta de dados}

O contato com os pais ocorreu em quatro préescolas municipais de uma cidade de pequeno porte do interior de São Paulo. A entrevista junto aos pais ocorreu no local de preferência dos mesmos, sendo nas dependências das pré-escolas ou na casa dos participantes.

\section{Instrumentos}

Roteiro de Entrevista de Habilidades Sociais Educativas Parentais - RE-HSE-P (Bolsoni-Silva, Marturano \& Loureiro, 2011). O instrumento visa avaliar as habilidades sociais educativas parentais, das práticas educativas negativas, problemas de comportamento e habilidades sociais infantis, como também a influência das variáveis contextuais sobre o comportamento dos pais e dos filhos. Por meio do instrumento é possível obter três conjuntos de informações: frequência das habilidades sociais educativas; número de itens para avaliações de conteúdo do comportamento dos pais e dos filhos e frequência para avaliações de conteúdo do comportamento dos pais e dos filhos.

Questionário de Relacionamento Conjugal(BolsoniSilva \& Marturano, 2010). O instrumento é composto por uma escala tipo Likert com 121 itens, sendo estes referentes à definição do cônjuge, formas de expressão de carinho entre o casal, diálogo e características da comunicação entre o casal, características positivas e negativas do cônjuge e avaliação da relação conjugal. As questões buscam tomar conhecimento da frequência em que o comportamento ocorre e as características do comportamento. Para os itens de frequência, existem três alternativas de resposta, sendo: $(\mathrm{F})$ frequentemente; (A) algumas vezes e $(\mathrm{N})$ nunca ou quase nunca. O instrumento permite obter o escore total e para cada um dos temas. Em todas as questões, exceto a de avaliação conjugal, é avaliada a frequência do comportamento, sendo três opções de resposta: frequentemente, algumas vezes ou nunca/quase nunca. $\mathrm{O}$ respondente deve se basear na frequência do comportamento durante a semana para escolher a opção de resposta.

Para análise da consistência interna da escala, foram considerados os itens com dados contínuos coletados neste estudo, resultando em um $\alpha=0,90$.

Questionário de Capacidades e Dificuldades $S D Q$ (elaborado por Goodman, 1997 e validado para o contexto brasileiro por Fleitlich-Bilyk \& Goodman,
2001): É um instrumento utilizado para rastreamento de problemas comportamentais e as capacidades de crianças e adolescentes (quatro a 16 anos).O questionário é composto por 25 itens, contidos em cinco escalas: Sintomas Emocionais, Problemas de Conduta, Hiperatividade, Problemas de Relacionamento com Colegas e Comportamento Pró-social (apenas a escala Comportamento Pró-Social é positiva, as demais escalas são negativas). As alternativas para resposta são expostas em cada questão e apresentam como opções: falso, mais ou menos verdadeiro e verdadeiro.

\section{Procedimento de coleta de dados}

Primeiramente, a pesquisadora entrou em contato com a diretora de cada pré-escola $(\mathrm{N}=4)$ para explicar sobre a pesquisa, seus objetivos e procedimentos de coleta de dados. Após o consentimento das diretoras, a pesquisadora entrou em contato com os pais, que se deu por meio da sua participação em reuniões escolares. Com os pais que demonstraram interesse em participar da pesquisa, foi agendado o horário para a realização da entrevista.

Todos os participantes receberam o Termo de Consentimento Livre e Esclarecido e explicações sobre a pesquisa antes de iniciar a coleta de dados. Com os pais, a pesquisadora pediu autorização para que a entrevista sobre as habilidades sociais educativas fosse gravada, seguindo a instrução do manual do instrumento utilizado e fornecendo as instruções. A coleta de dados feita com os outros instrumentos foram feitas em forma de entrevista, mas não foi gravada. Sendo assim, após a entrevista com cada pai, a pesquisadora ouviu as entrevistas para preenchimento do instrumento.

\section{Procedimento de análise de dados}

Para a análise dos dados obtidos por meio do Questionário de Relacionamento Conjugal, é atribuído o valor "0" para as respostas "nunca", "1" para algumas vezes e "2" para frequentemente. No presente trabalho será apresentado o valor total para cada subescala, sendo que, cada subescala pode variar de pontuação. No Questionário de Capacidades e Dificuldades, os valores atribuídos são 0 para falso, 1 para mais ou menos verdadeiro e 2 para verdadeiro. É realizada a soma dessa pontuação para a classificação dos comportamentos em clínico, limítrofe e não clinico, segundo o instrumento. No presente trabalho optou-se por não utilizar essas classificações, mas sim o escore obtido pela soma das médias.

Para avaliar as relações entre as variáveis paternas e os comportamentos infantis foi utilizado o teste de correlação de Pearson. O nível de significância adotado foi de $p<0,05$, para as análises de correlações. Para 
a realização dos testes foi utilizado o SPSS para Windows.

\section{RESULTADOS E DISCUSSÃO}

A Tabela 1 apresenta a classificação para as habilidades sociais educativas paternas em porcentagem.

TABELA 1

Classificação para análise por frequência (perguntas gerais) das habilidades sociais educativas paternas

\begin{tabular}{lccc}
\hline \multirow{2}{*}{ Sub-escala } & \multicolumn{3}{c}{$(N=40)$} \\
\cline { 2 - 4 } & $\begin{array}{c}\text { Clínico } \\
(\%)\end{array}$ & $\begin{array}{c}\text { Limitrofe } \\
(\%)\end{array}$ & $\begin{array}{c}\text { Não clínico } \\
(\%)\end{array}$ \\
\hline Habilidades sociais & 32,5 & 17,5 & 50 \\
educativas parentais & 15 & 22,5 & 62,5 \\
Habilidades sociais infantis & 15 & 10 & 75 \\
Contexto & 30 & 12,5 & 57,5 \\
Práticas negativas & 7,5 & 7,5 & 85 \\
Problema de comportamento & 0 & 2,5 & 97,5 \\
Total positivo & 35 & 7,5 & 57,5 \\
Total negativo & & & \\
\hline
\end{tabular}

De acordo com os dados da Tabela 1, percebese que, de forma geral, os comportamentos paternos obtiveram classificação não clínica, ou seja, parece que os pais avaliam seus próprios comportamentos de forma positiva. No entanto, as classificações para as habilidades sociais educativas parentais e o total negativo obtiveram escores relativamente elevados. É possível supor a partir desses dados que, parte dos participantes emita com frequência elevada comportamentos inadequados na interação com os filhos. É comum que quando os pais não têm um repertório elaborado de habilidades sociais educativas, acabam emitindo práticas inadequadas na tentativa de educar a prole, o que por consequência pode acarretar em problemas comportamentais dos filhos (Bortolini; Andretta, 2013). A Tabela 2 apresenta as médias das escalas referentes à avaliação da relação conjugal pelos pais.

A partir dos dados da Tabela 2, pode-se notar que os pais avaliaram positivamente as características de seus cônjuges e do relacionamento, ou seja, as variáveis positivas analisadas apresentaram escores mais elevados do que as variáveis negativas. $\mathrm{O}$ fato de os pais reconhecerem esses aspectos positivos nas esposas, como na relação conjugal contribuem para que o casal viva em harmonia, o que por sua vez, pode vir a colaborar para um lar sem conflitos, o que é positivo para o desenvolvimento infantil. $\mathrm{O}$ fato de os homens reconhecerem mais aspectos positivos é importante, pois de acordo com Dessen e Braz (2005) a percepção positiva reflete um efeito mais intenso na satisfação conjugal do que a percepção negativa, além da influência que a percepção do outro acarreta na qualidade e estabilidade do relacionamento. A Tabela 3 apresenta as médias para as escalas do SDQ.

TABELA 2

Medidas de tendência central das variáveis do relacionamento conjugal, segundo a opinião dos pais

\begin{tabular}{lc}
\hline \multicolumn{1}{c}{ Item $^{*}$} & Total \\
\hline Definição positiva do cônjuge & 25,76 \\
Características positivas da cônjuge & 23,06 \\
Cônjuge expressa sentimentos ao pai & 22,26 \\
Expressa sentimentos a cônjuge & 21,47 \\
Aspectos positivos da comunicação & 20,60 \\
Características positivas do relacionamento conjugal & 19,80 \\
Características negativas da cônjug & 7,44 \\
Aspectos negativos da comunicação & 6,12 \\
Definição negativa do cônjuge & 4,53 \\
\hline & Média \\
\hline Avaliação da relação conjugal** & 1,55 \\
\hline
\end{tabular}

* A pontuação para a subescala 'definição positiva da companheira' pode variar de 0 a 30; para a definição negativa da companheira de 0 a 12; para a de expressão de sentimentos para e pela companheira, de 0 a 28; para características positivas da comunicação, de 0 a 24; características negativas da comunicação, de 0 a 16; para a de características positivas da cônjuge e características do relacionamento conjugal, de 0 a 26 ; para as características negativas da companheira, de 0 a 22 .

** O item avaliação da relação conjugal, pode variar de 0 a 2 , sendo 0 para 'insatisfatória', 1 para 'regular' e 2 para 'satisfatória'.

TABELA 3

Medidas de tendência central para as escalas do SDQ, segundo a opinião dos pais

\begin{tabular}{lc}
\hline \multicolumn{1}{c}{ Item } & Média \\
\hline Sintomas emocionais & 3,15 \\
Problemas de conduta & 2,15 \\
Hiperatividade & 4,92 \\
Problemas de relacionamento com colegas & 1,52 \\
Comportamento pró-social & 8,82 \\
Pontuação total das dificuldades & 11,72 \\
\hline
\end{tabular}

Nota: Cada escala pode variar de 0 a 10 . A escala Pontuação total das dificuldades é calculada com base nas quatro primeiras escalas do instrumento, podendo variar de 0 a 40 .

Como visto na Tabela 3, a escala referente aos problemas de relacionamento com colegas apresentou a menor média, enquanto que a maior foi referente a pontuação total das dificuldades. O fato de a escala de relacionamento com colegas ter sido com menor 
média, pode estar relacionado ao fato de os pais não presenciarem muito o convívio dos filhos com os pares. Ressalta-se também para o fato de os comportamentos pró-sociais terem sido avaliados positivamente, pois mostra que as crianças deste estudo podem apresentar comportamentos inadequados, mas também têm uma frequência alta de comportamentos adequados. A Tabela 4 apresenta as correlações significativas entre as escalas de relacionamento conjugal e as habilidades sociais educativas paternas.

A partir dos dados expostos na Tabela 4, nota-se de maneira geral que os aspectos positivos do relacionamento conjugal apresentaram correlações positivas com as classificações das habilidades sociais educativas paternas, habilidades sociais infantis, variáveis de contexto, problemas de comportamento e total negativo. Sendo assim, entende-se que, quanto mais aspectos positivos na relação do casal, melhor também as habilidades sociais educativas na interação com os filhos e baixo uso de práticas nega- tivas (Braz, Dessen, \& Silva, 2005; Cummings \& O'Reilly, 1997; Garcia, Marin, \& Currea 2006; Cid, 2011). A Tabela 5 apresenta as correlações significativas entre as habilidades sociais educativas paternas e os problemas de comportamento dos filhos, na opinião de pais.

Como mostram os dados da Tabela 5, quanto melhor a classificação das habilidades sociais infantis e do total negativo, menor o índice de problemas de conduta, de relacionamento com colegas e a pontuação total das dificuldades. As práticas negativas utilizadas pelos pais apresentaram correlações negativas com as escalas de sintomas emocionais, problemas de conduta, de relacionamento com os colegas e pontuação total das dificuldades. A classificação dos problemas de comportamento infantis apresentou correlação positiva com os comportamentos pró-sociais das mesmas. A classificação do total positivo, por sua vez, apresentou correlação negativa com os problemas de relacionamento com colegas.

TABELA 4

Correlações significativas entre as escalas de relacionamento conjugal e as habilidades sociais educativas paternas

\begin{tabular}{|c|c|c|c|c|c|c|}
\hline & $H S E-P$ & HS infantis & $\begin{array}{l}\text { Variáveis de } \\
\text { contexto }\end{array}$ & $\begin{array}{l}\text { Práticas } \\
\text { negativas }\end{array}$ & $\begin{array}{c}\text { Problemas de } \\
\text { comportamento }\end{array}$ & Total negativo \\
\hline Avaliação da relação conjugal & $0,376^{*}$ & $0,428 * *$ & - & $0,368^{*}$ & - & $0,602 * *$ \\
\hline Definição negativa do cônjuge & $-0,346^{*}$ & - & - & $-0,468 * *$ & - & $-0,477 * *$ \\
\hline Definição positiva do cônjuge & - & $0,480 * *$ & - & - & - & $0,325^{*}$ \\
\hline Expressa sentimentos a cônjuge & $0,364 *$ & $0,374 *$ & $0,352 *$ & $0,499 * *$ & - & $0,590 * *$ \\
\hline Cônjuge expressa sentimentos ao marido & - & $0,361^{*}$ & - & $0,386^{*}$ & - & $0,510 * *$ \\
\hline Aspectos negativos da comunicação & $-0,345^{*}$ & $-0,329 *$ & - & $-0,461 * *$ & $-0,419 * *$ & $-0,511 * *$ \\
\hline Características positivas da cônjuge & - & $0,383^{*}$ & - & $0,389^{*}$ & - & $0,502 *$ \\
\hline $\begin{array}{l}\text { Características positivas do } \\
\text { relacionamento conjugal }\end{array}$ & - & $0,317^{*}$ & - & $0,361^{*}$ & - & $0,457 * *$ \\
\hline
\end{tabular}

$* p<0,05 ; * * p<0,01 ; * * *<0,001$.

TABELA 5

Correlações significativas entre habilidades sociais educativas paternas e problemas de comportamento dos filhos na opinião de pais

\begin{tabular}{|c|c|c|c|c|c|}
\hline & $\begin{array}{l}\text { Sintomas } \\
\text { emocionais }\end{array}$ & $\begin{array}{l}\text { Problemas } \\
\text { de conduta }\end{array}$ & $\begin{array}{l}\text { Problemas de } \\
\text { relacionamento } \\
\text { com colegas }\end{array}$ & $\begin{array}{c}\text { Comportamentos } \\
\text { pró-sociais }\end{array}$ & $\begin{array}{l}\text { Pontuação total } \\
\text { das dificuldades }\end{array}$ \\
\hline Habilidades sociais infantis & - & $-0,316^{*}$ & $-0,323^{*}$ & - & $-0,370^{*}$ \\
\hline Práticas negativas & $-0,323^{*}$ & $-0,435^{* *}$ & $-0,327^{*}$ & - & $-0,442 * *$ \\
\hline Problemas de comportamento infantis & - & - & - & $0,368^{*}$ & - \\
\hline Total positivo & - & - & $-0,314 *$ & - & - \\
\hline Total negativo & - & $-0,567 * * *$ & $-0,327 *$ & - & $-0,452 * *$ \\
\hline
\end{tabular}

$* p<0,05 ; * * p<0,01 ; * * * p<0,001$. 
Tais dados são indicativos de que um repertório de habilidades sociais infantis elaborado colabora para a emissão de comportamentos sociais, diminuindo os problemáticos (Del Prette \& Del Prette, 2005). No que se refere à relação entre os comportamentos paternos e infantis, os dados levam a indicar que pais que apresentam um bom repertório de habilidades sociais educativas, tendem a emitir com baixa frequência práticas negativas na interação com os filhos, o que parece estar influenciando para a não emissão de comportamentos problemáticos pelas crianças. Levanta-se a hipótese de que esses pais ao apresentarem comportamentos adequados na interação com sua prole estão oferecendo modelos de interação social às crianças, além de provavelmente consequenciar seus comportamentos adequados positivamente (BolsoniSilva, 2003). A Tabela 6 mostra as correlações entre os comportamentos infantis na opinião dos pais e as características do relacionamento conjugal.

De acordo com os dados da Tabela 6, a expressão de sentimentos do pai à sua cônjuge esteve negativamente correlacionada com os problemas de conduta e com a pontuação total das dificuldades dos filhos e positivamente correlacionada com os comportamentos pró-sociais dos filhos, ou seja, quanto maior a frequência de expressão de sentimentos do pai para sua companheira, menor o índice de problemas de conduta e maior a emissão de comportamentos pró-sociais dos filhos. Os aspectos negativos da comunicação entre o casal correlacionaram positivamente com os problemas de relacionamento com os colegas e negativamente com comportamentos pró-sociais dos filhos, segundo a opinião dos pais.

Em relação às variáveis do relacionamento conjugal, notou-se que a expressão de sentimentos entre o casal, colabora para diminuir o índice de problemas de conduta, de relacionamento com colegas e a pontuação total das dificuldades apresentadas pelas crianças, enquanto que o índice de comportamentos pró-sociais aumenta. Acredita-se que quando os pais têm boa relação conjugal, acabam apresentando modelos de interação para suas crianças, além de oferecer um lar harmonioso. A expressão de carinho entre o casal é de extrema importância para o desenvolvimento infantil, uma vez que pais que mantêm uma relação afetuosa com o cônjuge tendem a serem carinhosos também na relação com os filhos (Cummings \& O'Reilly, 1997), além de assegurarem a estes um lar seguro e afetuoso.

Os aspectos negativos da comunicação entre o casal apresentaram correlações positivas com os problemas de relacionamento com colegas e negativa com os comportamentos pró-sociais. Acredita-se que quando os filhos presenciam este modelo inadequado de comunicação entre os pais, eles aprendem a se comportar de tal forma, sendo provável a emissão deste padrão comportamental na interação com os pares, o que pode dificultar a emissão de comportamentos sociais. Tais dados corroboram com os achados dos estudos de Braz, Dessen e Silva (2005) e Schudlich, Shamir e Cummings (2004) que apontam para a relação entre conflitos conjugais e problemas de comportamento. $\mathrm{O}$ modo que os pais se comportam são modelos para os filhos, por isso, acredita-se que quanto mais positiva a relação conjugal, melhor também o repertório comportamental dos filhos.

\section{CONSIDERAÇÕES FINAIS}

Os resultados encontrados no presente estudo apontam para indicadores dos comportamentos paternos relacionados com o repertório comportamental das crianças. De modo geral, notou-se que quanto melhor a avaliação das habilidades sociais educativas, menor o índice de comportamentos problemáticos dos filhos e maior suas capacidades, ou seja, pode-se dizer que os comportamentos parentais, como conversar com o filho, dizer não e explicar o por quê, brincar, interagir com a criança, entre outros são facilitadores de comportamentos adequados nas crianças. No que se refere às relações encontradas entre as habilidades sociais educativas e as variáveis do relacionamento

TABELA 6

Correlações significativas entre as escalas de relacionamento conjugal e comportamentos infantis na opinião de pais

\begin{tabular}{lcccc}
\hline & \multicolumn{2}{c}{ Teste de Pearson r } \\
\cline { 2 - 5 } & $\begin{array}{c}\text { Problemas de } \\
\text { conduta }\end{array}$ & $\begin{array}{c}\text { Problemas de } \\
\text { relacionamento } \\
\text { com colegas }\end{array}$ & $\begin{array}{c}\text { Comportamentos } \\
\text { pró-sociais }\end{array}$ & $\begin{array}{c}\text { Pontuação total } \\
\text { das dificuldades }\end{array}$ \\
\hline Expressa sentimentos a parceira & $-0,345^{*}$ & - & $0,504^{* *}$ & $-0,355^{*}$ \\
Aspectos negativos da comunicação & - & $0,325^{*}$ & $-0,376^{*}$ & - \\
\hline
\end{tabular}

$* p<0,05 ; * * p<0,01$. 
conjugal, percebeu-se que quanto melhor a avaliação do relacionamento conjugal e mais características positivas reconhecidas pelo homem, melhor suas habilidades sociais educativas.

Vale ressaltar que este estudo é de caráter correlacional, ou seja, não sendo possível estabelecer causa e efeito entre as variáveis. De qualquer forma, acredita-se que se tratam de relações bidirecionais. Pode-se concluir que, além das habilidades sociais educativas dos pais, existem outras variáveis que influenciam a relação pai-filho, entre elas, encontra-se o relacionamento conjugal, que quanto mais satisfatório e mais características positivas presentes, melhor a relação também com a prole. Desta forma, acreditase que intervenções com pais que visem o ensino e/ou manutenção de suas práticas parentais, mais especificamente, as habilidades sociais educativas, assim como, que abordem questões referentes ao relacionamento conjugal, possam melhorar também o repertório comportamental infantil. Aponta-se ainda como limitação o número de participantes. Pesquisas futuras podem procurar ampliar o número de participantes, como por exemplo, pesquisar pais de crianças de outras faixas etárias, como também procurar avaliar os comportamentos dos pais na visão dos filhos.

\section{REFERÊNCIAS}

Benetti, S. P. C. (2006). Conflito conjugal: impacto no desenvolvimento psicológico da criança e do adolescente. Psicologia: Reflexão e Crítica, 19(2), 261-268. http://dx.doi.org/10.1590/S0102-79722006000200012

Bolsoni-Silva, A. T. (2003). Habilidades sociais educativas, variáveis contextuais e problemas de comportamento: Comparando pais e mães de pré-escolares (Tese de Doutorado não publicada). Faculdade de Filosofia, Ciências e Letras da Universidade de São Paulo, Ribeirão Preto, Brasil.

Bolsoni-Silva, A. \& Loureiro, S. R. (2010). Validação do roteiro de entrevista de habilidades sociais educativas parentais (RE-HSE-P). Avaliação Psicológica, 9(1), 63-75.

Bolsoni-Silva, A.T. \& Loureiro, S. R. (2011). Práticas educativas parentais e o repertório comportamental infantil: comparando crianças diferenciadas pelo comportamento. Paidéia, 21(48), 61-71.

Bolsoni-Silva, A. T. \& Marturano, E. M. (2010). Questionário de Relacionamento Conjugal (material cedido pelos autores).

Bolsoni-Silva, A., Paiva, M., \& Barbosa, C. (2009). Problemas de comportamento de crianças/adolescentes e dificuldades de pais/cuidadores: um estudo de caracterização. Psicologia Clínica, 21(1), 169-184. http://dx.doi.org/10.1590/S010356652009000100012

Bolsoni-Silva, A.T. \& Marturano, E. M. (2010). Relacionamento conjugal, problemas de comportamento e habilidades sociais de pré-escolares. Psicologia: Teoria e Pesquisa, 26(1), 67-75. http://dx.doi.org/10.1590/S010237722010000100009

Bolsoni-Silva, A.T., Marturano, E. M., \& Loureiro, S. R. (2011). Roteiro de Entrevista de Habilidades Sociais Parentais - RE-HSE-P. São Paulo: Vetor.

Bortonili, M. \& Andretta, I. (2013). Práticas parentais coercitivas e as repercussões nos problemas de comportamento dos filhos. Psicologia Argumento, 31(73), 227-235.

Braz, M. P., Dessen, M.A., \& Silva, N.L.P. (2005). Relações conjugais e parentais: uma comparação entre famílias de classes sociais baixa e média. Psicologia: Reflexão e Crítica, 18(2), 151-161. http://dx.doi.org/10.1590/S010279722005000200002

Caballo, V. E. (2003). Manual de avaliação e Treinamento das Habilidades sociais. São Paulo: Editora Santos.

Chan, K. L. (2011). Children exposed to child maltreatment and intimate partner violence: A study of co-occurrence among Hong Kong Chinese families. Child Abuse \& Neglect, 35, 532-542. http://dx.doi.org/10.1016/j.chiabu.2011.03.008

Cia, F., Barham, E. J., \& Fontaine, A. M. G. V. (2010). Impactos de uma intervenção com pais: o desempenho acadêmico e comportamento das crianças na escola. Psicologia: Reflexão e Crítica, 23(3), 533-543. http://dx.doi.org/10.1590/ S0102-79722010000300014

Cia, F. \& Barham, E. J. (2009). O envolvimento paterno e o desenvolvimento social de crianças iniciando as atividades escolares. Psicologia em Estudo, v. 14, n. 1, p. 67-74. http://dx.doi.org/10.1590/S1413-73722009000100009

Cid, M. F. B. (2011). Saúde mental de escolares: um estudo de prevalência e de fatores de risco e proteção. (Tese de Doutorado não publicada). Programa de Pós-Graduação em Educação Especial, Universidade Federal de São Carlos, São Carlos, Brasil.

Cummings, E. M. \& O’Reilly, A. (1997). Fathers in family context: Effects of marital quality adjustment. In M. E. Lamb (Org.), The role of the father in child developmental (pp. 196-221). New York: John Wiley \& Sons.

De Oliveira, A. G. \& Silva, R. R. (2011). Pai contemporâneo: Diálogos entre pesquisadores brasileiros no período de 1998 a 2008. Psicologia Argumento, 29(66), 353-360.

Del Prette, Z. A. P. \& Del Prette, A. (2005). Psicologia das habilidades sociais na infância: teoria e prática. Petrópolis: Vozes. 
Del Prette, Z. A. P. \& Del Prette, A. (2001). Psicologia das relações interpessoais: Vivências para o trabalho em grupo. Petrópolis: Vozes.

Dessen, M. A. \& Braz, M. P. (2000). Rede social de apoio durante transições familiares decorrentes do nascimento de filhos. Psicologia: Teoria e Pesquisa, 16(3), 221-231. http://dx.doi.org/10.1590/S0102-37722000000300005

Dessen, M. A. \& Braz, M. P. (2005). As relações maritais e sua influência nas relações parentais: implicações para o desenvolvimento da criança. In M. A. Dessen, A. L. Costa Junior (Orgs). A ciência do desenvolvimento humano (pp.132-151). Porto Alegre: Artmed.

Durand, J. G., Schraiber, L. B., França-Junior, I., \& Barros, C. (2011). Repercussão da exposição à violência por parceiro íntimo no comportamento dos filhos. Revista de Saúde Pública, 45(2), 355-364.

Emery, R. E. \& Tuer, M. D. (1993). Parenting and the marital relationship. In T. Luster \& L. Okagaki (Orgs.). Parenting an ecological perspective (pp. 121-148). Hillsdate: Lauvrence Eilbaum.

Gargiulo, R. M. (2003). Special Education in Contemporary Society - an introduction to exceptionality. Belmont (CA): Wadsworth/Thomson Learning.

Goodman, R. (1997). The Strengths and Difficulties Questionnaire: A research note. Journal of Child Psychology and Psychiatry, 38(65), 581-586. http://dx.doi.org/10.1111/j.1469-7610.1997.tb01545.x

Gresham, F. M. (2009). Análise do comportamento aplicada às habilidades sociais. In Z. A. P. Del Prette, A. Del Prette, (Orgs.). Psicologia das habilidades sociais: diversidade teórica e suas implicações (pp. 17-66). Petrópolis: Vozes.

Leme, V. \& Bolsoni-Silva, A.T. (2010). Habilidades Sociais Educativas Parentais e comportamentos de pré-escolares. Estudos de Psicologia, 15(2), 161-173. http://dx.doi.org/10.1590/S1413-294X2010000200005

Lindsey, E. W., Caldera, Y. M., \& Iankersley, L. (2009). Marital conflict and the quality of young children's peer play behavior: the mediating and moderating role of parent-child emotional reciprocity and attachment security. Journal of Family Psychology, 23(2), 130-145. http://dx.doi.org/10.1037/a0014972

Loss, H. \& Cassemiro, L. F. K. (2010). Percepções sobre a qualidade da interação familiar e crenças autorreferenciadas em crianças. Estudos de Psicologia, 27(3), 293-303.

Silva, A. \& Cia, F. (2012). Problemas de Comportamento: conceituação e possibilidades de intervenções para pais e pofessores. Jundiaí, SC: Paco Editorial.

Villas Boas, A. C. V. B., Dessen, M. A., \& Melchiori, L. E. (2010). Conflitos conjugais e seus efeitos sobre o comportamento de crianças: uma revisão teórica. Arquivos Brasileiros de Psicologia, 62(2), 91-112.

Schudlich, T. D. D. R., Shamir, H., \& Cummings, E. M. (2004). Marital Conflict, Children's Representations of Family Relationships, and Children's Dispositions Towards Peer Conflict Strategies. Social Development, 13(2), 171-192. http://dx.doi.org/10.1111/j.1467-9507.2004.000262.x

Slack, K. S., Berger, L. M., Dumont, K., Yang, M. Y., Kim, B., Ehrhard-Dietzel, S., \& Holl, J. L. (2011). Risk and protective factors for child neglect during early childhood: A cross-study comparison. Children and Youth Services Review, 33, 1354-1363. http://dx.doi.org/10.1016/j.childyouth.2011.04.024

Autores:

Aline Costa FAnTINATO - Doutorando na Universidade Federal de São Carlos.

FABIANA CIA - Doutor na Universidade Federal de São Carlos.

Endereço para correspondência:

Aline Costa Fantinato

Rua Dr. Moretz Shons, 690 apto 51 - Bloco A - Vila Guimarães

13630-170 Pirassununga, SP, Brasil

Recebido em: 18.05 .14

Aceito em: 28.10 .14 